\title{
Efficacy of two endectoparasiticide products combining fipronil and (S)-methoprene or esafoxolaner with eprinomectin and praziquantel against fleas and intestinal helminths in cats naturally infested in Brazil
}

Andre A. Cutolo ${ }^{1}$, Debora T.G. Jardina ${ }^{1}$, Gabriela G. De Vito ${ }^{2}$, Cristiano Grisi do Nascimento ${ }^{3}$, Maycon Junior Heidmann ${ }^{4}$, José Dirceu Ferreira Nantes ${ }^{4}$, Karolyne Vieira Bassetto ${ }^{4}$, Isabella Cristina Chagas ${ }^{4}$, Edgar Ferreira Pereira Junior ${ }^{4}$, Bruno Gomes de Castro ${ }^{4}$, and Eric Tielemans ${ }^{5, *}$

${ }^{1}$ Boehringer-Ingelheim Animal Health, Fazenda São Francisco, 13140-000 Paulinia, SP, Brazil

2 ICON Global Strategic Solutions, 1308 avenue Doutor Cardoso de Melo, 04548-004 São Paulo, SP, Brazil

${ }^{3}$ Convolution Divisão de Antiparasitários, 150 Lauro Valente Street, Cond Saint Gerard, 14022-048 Ribeirão Preto, SP, Brazil

${ }^{4}$ Universidade Federal de Mato Grosso, 1200 Alexandre Ferronato Avenue, 78557-267 Sinop, MT, Brazil

5 Boehringer-Ingelheim Animal Health, 29 avenue Tony Garnier, 69007 Lyon, France

Received 14 October 2021, Accepted 17 February 2022, Published online 3 March 2022

\begin{abstract}
Eprinomectin and praziquantel, nematodicide and cestodicide compounds, are both combined with the insecticide and acaricide compounds fipronil and (S)-methoprene in Frontline ${ }^{\circledR}$ Protect/Broadline ${ }^{\circledR}$, or esafoxolaner in NexGard ${ }^{\circledR}$ Combo. These topical feline endectoparasiticide products were tested for efficacy against fleas and intestinal helminths in a field trial in Brazil. Flea- and/or helminth-infested domestic cats were treated twice at a monthly interval following label instructions: 160 cats with Frontline ${ }^{\circledR}$ Protect/Broadline ${ }^{\circledR}$ and 165 cats with NexGard $^{\circledR}$ Combo. The flea and intestinal helminth infestations were evaluated using comb counts and copromicroscopy, respectively before first treatment for baseline value, then 9 and 30 days after each treatment for fleas, and 9 days after each treatment for helminths. Multiparasitism was very frequent at baseline, as amongst the 325 included cats, 295, 280, 86 and 93 cats were at least infested with Ctenocephalides fleas, Ancylostoma, Toxocara and Dipylidium caninum, respectively. Efficacies were calculated by comparing the geometric means at baseline and at post-treatment timepoints for each parasite genus/species. Inclusive of both products and of all evaluation timepoints, the Ctenocephalides, Ancylostoma, Toxocara and D. caninum efficacies were at least $98.3 \%, 99.8 \%, 99.8 \%$ and $96.3 \%$, respectively. No adverse reactions were observed, except for a few instances of mild, transient, and self-resolving hypersalivation occurring on the day of treatment in both groups. This field trial demonstrated high-level efficacy of Frontline ${ }^{\circledR}$ Protect/Broadline ${ }^{\circledR}$ and NexGard ${ }^{\circledR}$ Combo against major parasites of cats in Brazil.
\end{abstract}

Key words: Cat, Efficacy, Flea, Frontline ${ }^{\circledR}$ Protect/Broadline ${ }^{\circledR}$, Intestinal helminth, NexGard ${ }^{\circledR}$ Combo.

Résumé - Efficacité de deux produits endectoparasiticides associant fipronil et (S)-méthoprène ou esafoxolaner à l'éprinomectine et au praziquantel contre les puces et les helminthes intestinaux chez les chats naturellement infestés au Brésil. L'éprinomectine et le praziquantel, composés nématodicides et cestodicides, sont tous les deux associés aux composés insecticides et acaricides fipronil et (S)-méthoprène dans Frontline ${ }^{\circledR}$ Protect/Broadline ${ }^{\circledR}$, ou esafoxolaner dans NexGard ${ }^{\circledR}$ Combo. Ces produits endectoparasiticides félins topiques ont été testés pour leur efficacité contre les puces et les helminthes intestinaux lors d'un essai sur le terrain au Brésil. Des chats domestiques infestés de puces et/ou d'helminthes ont été traités deux fois à intervalle d'un mois en suivant les instructions d'utilisation, 160 chats avec Frontline ${ }^{\circledR}$ Protect/Broadline ${ }^{\circledR}$ et 165 chats avec NexGard ${ }^{\circledR}$ Combo. Les infestations par les puces et les helminthes intestinaux ont été évaluées en utilisant respectivement par comptage au peigne et par copromicroscopie, avant le premier traitement pour la valeur de base, puis 9 et 30 jours après chaque traitement pour les puces, et 9 jours après chaque traitement pour les helminthes. Le multiparasitisme était très fréquent à l'inclusion puisque parmi les 325 chats inclus, 295, 280, 86 et 93 chats étaient au moins infestés respectivement par les puces

*Corresponding author: eric.tielemans@boehringer-ingelheim.com

Special Issue - NexGard ${ }^{\circledR}$ Combo (esafoxolaner, eprinomectin, praziquantel): A new endectocide spot-on formulation for cats. Invited Editor: Frédéric Beugnet

This is an Open Access article distributed under the terms of the Creative Commons Attribution License (https://creativecommons.org/licenses/by/4.0), which permits unrestricted use, distribution, and reproduction in any medium, provided the original work is properly cited. 


\begin{abstract}
Ctenocephalides, ou Ancylostoma, Toxocara et Dipylidium caninum. Les efficacités ont été calculées en comparant les moyennes géométriques au départ et aux points d'évaluation post-traitement pour chaque genre/espèce de parasite. En incluant les deux produits et tous les points temporels d'évaluation, les efficacités contre Ctenocephalides, Ancylostoma, Toxocara et D. caninum étaient respectivement d'au moins 98,3\%, 99,8\%, 99,8\% et 96,3\%. Aucun effet indésirable n'a été observé à l'exception de quelques cas d'hypersalivation légère, transitoire et auto-résolvante survenant le jour d'un traitement dans les deux groupes. Cet essai sur le terrain a démontré une efficacité de haut niveau de Frontline ${ }^{\circledR}$ Protect / Broadline ${ }^{\circledR}$ et NexGard ${ }^{\circledR}$ Combo contre les principaux parasites des chats au Brésil.
\end{abstract}

\section{Introduction}

Frontline ${ }^{\circledR}$ Protect/Broadline ${ }^{\circledR}$ (abbreviated as "Broadline ${ }^{\circledR,}$ in the rest of the document), a combination of fipronil, (S)-methoprene, eprinomectin and praziquantel; and NexGard ${ }^{\circledR}$ Combo, a combination of esafoxolaner, eprinomectin and praziquantel are both topical endectoparasiticide products for cats aimed at the treatment and control of multiparasitism, a common condition in the feline species [2, 4, 16, 21]. Fipronil/ (S)-methoprene and esafoxolaner provide insecticide and acaricide properties, eprinomectin and praziquantel provide nematodicide and cestodicide properties, respectively. Broadline ${ }^{\circledR}$ has been used safely for several years [8] and was demonstrated to be efficacious against a broad spectrum of feline parasites, including fleas [1] and gastro-intestinal helminths [13, 24]. NexGard ${ }^{\circledR}$ Combo was recently developed and registered in the European Union [9] and was demonstrated to be efficacious against fleas in experimental infestation studies conducted with isolates originating from France, South Africa and the USA [25], and in field studies with naturally infested cats from Europe, the USA and Australia [27], and against gastrointestinal helminths using induced and natural models of infection with isolates originating from Europe, North America and South Africa [12]. The safety of NexGard ${ }^{\circledR}$ Combo was also comprehensively demonstrated, namely in specific target animal safety studies $[10,26]$.

It was necessary to confirm the efficacy of these two products against major feline parasites in South America, as the control of feline parasitism is important worldwide both for veterinary and public health $[6,28]$, and as authorities in major regions of the world require efficacy testing on local strains of parasites for registration of new products. This manuscript describes a field trial conducted in the Brazilian Southern Amazonian region for the investigation of the efficacy and tolerance of Broadline ${ }^{\circledR}$ and NexGard ${ }^{\circledR}$ Combo in cats naturally infested with fleas and/or intestinal helminths.

\section{Materials and methods Ethics}

The study protocol had been reviewed and approved by the sponsor's institutional animal care and use committee, and a license had been obtained from the local authorities.

\section{Study design}

This study was designed in accordance with the "World Association for the Advancement of Veterinary Parasitology
(W.A.A.V.P.) guidelines for evaluating the efficacy of parasiticides for the treatment, prevention and control of flea and tick infestation on dogs and cats" [17], the "WAAVP guidelines for evaluating the efficacy of anthelmintics for dogs and cats" [11], the International Cooperation on Harmonisation of Technical Requirements for Registration of Veterinary Medicinal Products VICH GL7, "Efficacy of Anthelmintics: General Requirements" [31], and VICH GL20 "Efficacy of Anthelmintics: Specific Recommendations for Felines" [32]. The study was conducted in accordance with Good Clinical Practices as described in "International Cooperation on Harmonization of Technical Requirements for Registration of Veterinary Medicinal Products (VICH) guideline GL9".

The objectives of the study were to confirm the safety and efficacy of Broadline ${ }^{\circledR}$ and NexGard ${ }^{\circledR}$ Combo after one and two successive monthly treatments, against fleas and intestinal helminths naturally acquired in the field in Brazil.

The study was conducted on domestic cats in urban areas of Mato Grosso and Pará states, Brazil. In Mato Grosso, 83 and 85 cats, and in Pará, 77 and 79 cats, were assigned to the Broadline ${ }^{\circledR}$ and NexGard ${ }^{\circledR}$ Combo groups, respectively.

To qualify for the study, a household had at least one cat naturally infested with six or more live fleas and/or intestinal helminth(s) (Ancylostoma and/or Toxocara eggs, and/or Dipylidium eggs or proglottids). A household could contain a maximum of five dogs and cats (to minimize environmental flea infestation bias, dogs were administered oral afoxolaner), and all cats from a household were treated with the same product. The cat or cats adequately infested were evaluated for efficacy and safety; any other cat with an insufficient or absent infestation was only evaluated for safety. Neither the cat(s) nor the environment had been treated with any parasiticide compound within two months of inclusion.

Allocation into the Broadline ${ }^{\circledR}$ or $\mathrm{NexGard}^{\circledR}$ Combo groups was performed by lottery (taking numbers out of a hat), being performed on blocks of two households. If the first household was randomized into one treatment, consequently the second was allocated to the other treatment group. The process was repeated for each new pair of households containing included cats. A total of 160 cats were included in the Broadline ${ }^{\circledR}$ group and 165 cats in the NexGard ${ }^{\circledR}$ Combo group. There was only one cat in a multi-pet household assigned to NexGard $^{\circledR}$ Combo that did not meet the infestation criteria; this cat was therefore treated, but evaluated only for safety.

Ninety percent of these 325 cats were infested with more than one parasite. In the Broadline ${ }^{\circledR}$ group, 146, 143, 42 and 46, and in the NexGard ${ }^{\circledR}$ Combo group, 149, 137, 44 and 47 evaluations of flea, Ancylostoma, Toxocara and Dipylidium infestations were conducted, respectively (Table 3). 


\section{Animals}

To qualify for inclusion, cats were to harbor a minimum of six fleas and/or helminth eggs/proglottids in feces, and were declared suitable for the study in terms of health by a veterinarian. The 325 included domestic cats were aged 2 months to 13 years, weighed $0.6-6.1 \mathrm{~kg}$, and were not limited by sex and reproductive status (neutered or intact). They were predominantly Domestic Short/or Long Hair, except for 9 Siamese, 3 Turkish Angora, and 1 Persian. Cats lived indoors, outdoors, or had both indoor and outdoor access; no housing restrictions were implemented and cats were fed as usual.

\section{Treatment}

Cats were treated by the Investigator on Days 0 and $30( \pm 2)$ at the recommended label dose of $0.3 \mathrm{~mL}$ (for cats weighing 0.8 to $<2.5 \mathrm{~kg}$ ), or $0.9 \mathrm{~mL}$ (for cats weighing 2.5 to $<7.5 \mathrm{~kg}$ ), which for Broadline ${ }^{\circledR}$ corresponded to $10.0-31.1 \mathrm{mg} / \mathrm{kg}$ fipronil, 12 $37.5 \mathrm{mg} / \mathrm{kg}$ (S)-methoprene, $0.48-1.50 \mathrm{mg} / \mathrm{kg}$ eprinomectin, and $10.0-31.1 \mathrm{mg} / \mathrm{kg}$ praziquantel, and for NexGard ${ }^{\circledR}$ Combo $1.44-4.5 \mathrm{mg} / \mathrm{kg}$ esafoxolaner, $0.48-1.50 \mathrm{mg} / \mathrm{kg}$ eprinomectin, and $10.0-31.1 \mathrm{mg} / \mathrm{kg}$ praziquantel. The treatments were applied as per respective labels, in one spot directly on the skin, after parting the hair, in the midline of the neck between the base of the skull and the shoulder blades.

\section{Parasite counts}

Flea counts were performed by systematically combing all parts of the cat using a fine-tooth flea comb for at least $5 \mathrm{~min}$. The counts were performed before the first treatment for baseline evaluation, then on Days $9( \pm 2), 30$ (before second treatment), 39 and 60 for efficacy evaluations.

Intestinal helminth evaluations (Ancylostoma sp., Toxocara $s p$. and Dipylidium $s p$.) were performed by copromicroscopy using McMaster and Centrifugal Flotation Techniques, for the expression of egg counts in eggs per gram (EPG). Dipylidium $s p$. evaluations were also performed by visual examination and count of proglottids in feces. The evaluations were performed on fecal samples obtained before the first treatment for baseline evaluation and inclusion, then on Days $9( \pm 2)$ and 39. Fecal samples were collected at the households, with proper care taken to confirm the origin in case of multi-cat households.

\section{Tolerance evaluations}

Owners were requested to observe their cats closely for $2 \mathrm{~h}$ after each treatment, then daily, and to report any abnormality to the veterinarian in charge. At each scheduled visit (Days 0, 9, 30, 39 and (flea only) 60), the Investigator performed a physical examination, which together with consideration of any adverse reactions reported by owners (resulting or not in an unplanned veterinary consultation, veterinary care, concurrent medication, etc.) was considered for an evaluation of the tolerance. Relationships to treatment for all adverse reactions and abnormalities were evaluated by the Investigator.

\section{Statistical analysis}

Total live flea counts, EPG and proglottid counts were transformed to the natural logarithm of (count +1$)$ for analysis and calculation of the geometric means. The percent efficacy was calculated using the formula $100 \times[(B-T) / B]$, where $B=$ geometric mean of the Day 0 (baseline) visit count and $T=$ geometric mean of the appropriate visit day count. The geometric mean was calculated by taking the anti-logarithm of the average of the log-counts and then subtracting 1 , or was computed by taking the anti-logarithm of the least square mean minus 1 from the analysis model. Flea efficacy was also calculated on the basis of arithmetic means.

\section{Results}

\section{Flea and intestinal helminth efficacies}

The flea efficacy results are presented in Table 1.

In the Broadline ${ }^{\circledR}$ group, the 146 cats evaluated for fleas were infested with 6-43 fleas at inclusion (geometric mean 11.4), and the percent reduction of live fleas compared to baseline, 9 and 30 days after each of the two treatments ranged from $98.3 \%$ to $99.7 \%$.

In the NexGard ${ }^{\circledR}$ Combo group, the 149 cats evaluated for fleas were infested with 6-31 fleas at inclusion (geometric mean 10.9), and the percent reduction of live fleas compared to baseline, 9 and 30 days after each of the two treatments ranged from $99.0 \%$ to $99.9 \%$.

The intestinal helminths efficacy results are presented in Table 2.

In the Broadline ${ }^{\circledR}$ group, the helminth efficacies evaluated nine days after each treatment exceeded $99 \%$ for nematodes (Ancylostoma and Toxocara) and $97 \%$ for Dipylidium.

In the Nexgard ${ }^{\circledR}$ Combo group, the helminth efficacies evaluated nine days after each treatment exceeded $99 \%$ for nematodes (Ancylostoma and Toxocara) and $96 \%$ for Dipylidium.

At inclusion, inclusive of both groups, most cats were infested by fleas $(91.0 \%)$, by helminths $(94.8 \%)$, and were mixed infested by fleas and helminths $(85.8 \%)$. The types and proportions of infestations including the mixed infestations are summarized in Table 3 and detailed in Table 4.

\section{Tolerance}

A total of 320 Broadline $^{\circledR}$ and $330 \mathrm{NexGard}^{\circledR}$ Combo treatments were administered.

In the Broadline ${ }^{\circledR}$ group, nine occurrences of mild and selfresolving hypersalivation were observed and lasted up to $40 \mathrm{~min}$ in eight instances, and $24 \mathrm{~h}$ one instance. No other adverse reactions were observed.

In the NexGard ${ }^{\circledR}$ Combo group, five occurrences of mild and self-resolving hypersalivation were observed and lasted up to $40 \mathrm{~min}$. No other adverse reactions were observed.

No animal needed or received any concurrent medication during the study. 
Table 1. Flea efficacy results.

\begin{tabular}{|c|c|c|c|c|c|c|}
\hline & $n$ cats & $\begin{array}{c}\text { Day } 0 \\
146\end{array}$ & $\begin{array}{c}\text { Day } 9 \\
146\end{array}$ & $\begin{array}{c}\text { Day } 30 \\
146\end{array}$ & $\begin{array}{c}\text { Day } 39 \\
146\end{array}$ & $\begin{array}{c}\text { Day } 60 \\
146\end{array}$ \\
\hline \multirow[t]{5}{*}{ Broadline $^{\circledR}$} & Geo Mean & 11.4 & 0.2 & 0.2 & 0.0 & 0.1 \\
\hline & $\%$ efficacy & & 98.5 & 98.3 & 99.7 & 99.4 \\
\hline & $p$-value & & $<0.0001$ & $<0.0001$ & $<0.0001$ & $<0.0001$ \\
\hline & A Mean & 12.2 & 0.3 & 0.4 & 0.1 & 0.1 \\
\hline & $\%$ efficacy & & 97.5 & 96.4 & 99.5 & 99.2 \\
\hline \multirow[t]{6}{*}{ NexGard ${ }^{\circledR}$ Combo } & $n$ cats & 149 & 149 & 149 & 149 & 149 \\
\hline & Geo Mean & 10.9 & 0.11 & 0.09 & 0.01 & 0.02 \\
\hline & $\%$ efficacy & & 99.0 & 99.2 & 99.9 & 99.8 \\
\hline & $p$-value & & $<0.0001$ & $<0.0001$ & $<0.0001$ & $<0.0001$ \\
\hline & A Mean & 11.5 & 0.19 & 0.15 & 0.02 & 0.03 \\
\hline & $\%$ efficacy & & 98.4 & 98.7 & 99.8 & 99.7 \\
\hline
\end{tabular}

Geo Mean $=$ geometric mean of flea counts; A Mean = arithmetic mean of flea counts.

${ }^{1}$ Percent efficacy $=100[(C-T) / C]$,

where $C$ is the geometric (Geo) mean at baseline (Day 0) and $T$ is the geometric mean at evaluation timepoints.

${ }^{2}$ Percent efficacy $=100[(C-T) / C]$, where $C$ is the arithmetic (A) mean at baseline (Day 0$)$ and $T$ is the geometric mean at evaluation timepoints.

${ }^{3}$ Two-sided probability value from analysis of variance on log-counts of the mean at baseline and evaluation timepoints.

Table 2. Gastro-intestinal helminths efficacy results.

\begin{tabular}{|c|c|c|c|c|c|c|c|c|c|c|}
\hline & \multicolumn{3}{|c|}{ Ancylostoma } & \multicolumn{3}{|c|}{ Toxocara } & \multicolumn{3}{|c|}{ Dipylidium caninum } \\
\hline & & Day 0 & Day 9 & Day 39 & Day 0 & Day 9 & Day 39 & Day 0 & Day 9 & Day 39 \\
\hline \multirow[t]{4}{*}{ Broadline $^{\circledR}$} & $n$ cats & 143 & 143 & 143 & 42 & 42 & 42 & 46 & 46 & 46 \\
\hline & Geo Mean & 459.2 & 0.9 & 0.3 & 190.9 & 0.2 & 0.1 & 1.6 & 0.0 & 0.0 \\
\hline & $\%$ efficacy & & 99.8 & 99.9 & & 99.9 & 99.9 & & 98.0 & 97.0 \\
\hline & $p$-value & & $<0.0001$ & $<0.0001$ & & $<0.0001$ & $<0.0001$ & & $<0.0007$ & $<0.0012$ \\
\hline \multirow[t]{4}{*}{ NexGard $^{\circledR}$ Combo } & $n$ cats & 137 & 137 & 137 & 44 & 44 & 44 & 47 & 47 & 47 \\
\hline & Geo Mean & 426.2 & 0.6 & 0.3 & 202.8 & 0.4 & 0.2 & 1.65 & 0.06 & 0.03 \\
\hline & $\%$ efficacy & & 99.9 & 99.9 & & 99.8 & 99.9 & & 96.3 & 98.2 \\
\hline & $p$-value & & $<0.0001$ & $<0.0001$ & & $<0.0001$ & $<0.0001$ & & $<0.0009$ & $<0.0006$ \\
\hline
\end{tabular}

Geo Mean = geometric mean of eggs per gram (EPG) for Ancylostoma and Toxocara, and proglottids for Dipylidium.

${ }^{1}$ Percent efficacy $=100[(C-T) / C]$, where $C$ is the geometric $(\mathrm{Geo})$ mean at baseline (Day 0$)$ and $T$ is the geometric mean at evaluation timepoints.

${ }^{2}$ Two-sided probability value from analysis of variance on log-counts of the mean at baseline and evaluation timepoints.

Table 3. Parasitism of cats and types of mixed infestations.

\begin{tabular}{|c|c|c|c|c|c|c|}
\hline & \multicolumn{2}{|c|}{ Broadline $^{\circledR}$} & \multicolumn{2}{|c|}{ NexGard Combo ${ }^{\circledR}$} & \multicolumn{2}{|c|}{ Total } \\
\hline & $n$ & $\%$ & $n$ & $\%$ & $n$ & $\%$ \\
\hline Fleas & 146 & 91.3 & 149 & 90.9 & 295 & 91.0 \\
\hline Helminths & 154 & 96.3 & 153 & 93.3 & 307 & 94.8 \\
\hline Nematodes & 146 & 91.3 & 141 & 86.0 & 287 & 88.6 \\
\hline Cestodes & 46 & 28.8 & 47 & 28.7 & 93 & 28.7 \\
\hline At least two parasites & 148 & 92.5 & 144 & 87.8 & 292 & 90.1 \\
\hline At least three parasites & 65 & 40.6 & 68 & 41.5 & 133 & 41.0 \\
\hline Fleas and helminths & 140 & 87.5 & 138 & 84.1 & 278 & 85.8 \\
\hline
\end{tabular}

\section{Discussion and conclusion}

This field trial confirmed that Broadline ${ }^{\circledR}$ or NexGard ${ }^{\circledR}$ Combo applied to cats in Brazil have a comparable and high level of efficacy against fleas, Ancylostoma and Toxocara infestations. The results also showed high efficacy against
D. caninum infections for both products, however, less conclusively as the detection methods used (copromicroscopy and visual examination of proglottids on feces) lack sensitivity and have been demonstrated to only reveal a fraction of the true infection incidence when compared to worm counts performed under necropsy [15]. Comparable efficacy was fully expected 
Table 4. Details of infestations at baseline.

\begin{tabular}{|c|c|c|c|c|c|c|}
\hline & \multicolumn{2}{|c|}{ Broadline $^{\circledR}$} & \multicolumn{2}{|c|}{$\begin{array}{c}\text { NexGard }^{\circledR} \\
\text { Combo }\end{array}$} & \multicolumn{2}{|c|}{ Total } \\
\hline & $n$ & $\%$ & $n$ & $\%$ & $n$ & $\%$ \\
\hline Fleas only & 6 & 3.8 & 11 & 6.7 & 17 & 5.2 \\
\hline Ancylostoma only & 6 & 3.8 & 8 & 4.9 & 14 & 4.3 \\
\hline Toxocara only & 0 & 0.0 & 0 & 0.0 & 0 & 0.0 \\
\hline Dipylidium only & 0 & 0.0 & 1 & 0.6 & 1 & 0.3 \\
\hline Ancylostoma and Toxocara & 7 & 4.4 & 4 & 2.4 & 11 & 3.4 \\
\hline Ancylostoma and Dipylidium & 1 & 0.6 & 0 & 0.0 & 1 & 0.3 \\
\hline Toxocara and Dipylidium & 0 & 0.0 & 2 & 1.2 & 2 & 0.6 \\
\hline Ancylostoma and Toxocara and Dipylidium & 0 & 0 & 0 & 0 & 0 & 0 \\
\hline Fleas and Ancylostoma & 64 & 40.0 & 58 & 35.4 & 122 & 37.7 \\
\hline Fleas and Toxocara & 3 & 1.9 & 1 & 0.6 & 4 & 1.2 \\
\hline Fleas and Ancylostoma and Toxocara & 28 & 17.5 & 35 & 21.3 & 63 & 19.4 \\
\hline Fleas and Dipylidium & 8 & 5.0 & 11 & 6.7 & 19 & 5.9 \\
\hline Fleas and Ancylostoma and Dipylidium & 33 & 20.6 & 31 & 18.9 & 64 & 19.8 \\
\hline Fleas and Toxocara and Dipylidium & 0 & 0.0 & 1 & 0.6 & 1 & 0.3 \\
\hline Fleas and Ancylostoma and Toxocara and Dipylidium & 4 & 2.5 & 1 & 0.6 & 5 & 1.5 \\
\hline Total number of cats & 160 & & 164 & & 324 & \\
\hline
\end{tabular}

$n=$ number of cats diagnosed positive for the parasite at baseline (before first treatment).

for both products with regards to intestinal helminths, as their active ingredients, eprinomectin and praziquantel, are identical and administered at the same dosage. Comparable efficacy was expected to a lesser extent with regards to fleas, as on the one hand esafoxolaner, the isoxazoline ectoparasiticide active ingredient of NexGard ${ }^{\circledR}$ Combo, is a novel systemic compound to which no fleas have yet been exposed in Brazil, while on the other fipronil, the ectoparasiticide active ingredient of Broadline ${ }^{\circledR}$, is a contact compound that has been used worldwide for several decades, including in Brazil, in several animal species, public hygiene, and also in crop agriculture. The high efficacy results of fipronil (in combination to (S)-methoprene) observed in the present field trial show that this ingredient remains a good tool to control fleas in Brazil.

This trial also confirmed that cats are a species commonly infested by multiple parasites, as referenced in Brazil $[14,18$, $19,23]$ and worldwide [2-4, 6, 7, 15, 21]. In the present study, $85.8 \%$ of domestic cats from an urban area were simultaneously infested with fleas and intestinal helminths, and $21.6 \%$ with fleas and intestinal nematodes and cestodes (Table 3). There was a gap in the epizootiological investigation of this study, as the incidences of Aelurostrongylus abstrusus and Troglostrongylus brevior, major lungworms of cats were not investigated. The specific diagnostic technique for $A$. abstrusus and $T$. brevior (Baermann funnel migration) was not performed due to study logistics; nevertheless, the worldwide importance $[20,29,30]$ including in Brazil $[5,22]$ of these feline lungworms should not be overlooked by the epizootiological observations of the present study.

These observations confirm the importance of using a broad endectoparasiticide medical strategy in cats, including ectoparasiticide, nematodicide and cestodicide treatments.

This field trial demonstrated a high level of tolerance and efficacy of Broadline ${ }^{\circledR}$ and NexGard ${ }^{\circledR}$ Combo against major parasites of cats in Brazil.
Acknowledgements. Thanks are due to all R\&D Boehringer Ingelheim Animal Health Brazil staff for their support in providing logistics and study data review.

\section{Competing interest}

The work reported herein was funded by Boehringer-Ingelheim. The authors are current employees or contractors of Boehringer-Ingelheim. Other than that, the authors declare no conflict of interest. This document is provided for scientific purposes only. Any reference to a brand or trademark herein is for information purposes only and is not intended for any commercial purposes or to dilute the rights of the respective owners of the brand(s) or trademark(s).

\section{References}

1. Baker C, Tielemans E, Prullage JB, Chester ST, Knaus M, Rehbein S, Fourie JJ, Young DR, Everett WR, Rosentel JK. 2014. Efficacy of a novel topical combination of fipronil, (S)-methoprene, eprinomectin and praziquantel against adult and immature stages of the cat flea (Ctenocephalides felis) on cats. Veterinary Parasitology, 202(1-2), 54-58. https://doi.org/ 10.1016/j.vetpar.2014.02.040. PMID: 24703078.

2. Beugnet F, Bourdeau P, Chalvet-Monfray K, Cozma V, Farkas R, Guillot J, Halos L, Joachim A, Losson B, Miró G, Otranto D, Renaud M, Rinaldi L. 2014. Parasites of domestic owned cats in Europe: co-infestations and risk factors. Parasites and Vectors, 7, 291.

3. Calvete C, Lucientes J, Castillo JA, Estrada R, Gracia MJ, Peribáñez MA, Ferrer M. 1998. Gastrointestinal helminth parasites in stray cats from the mid-Ebro Valley, Spain. Veterinary Parasitology, 75, 235-240.

4. Capári B, Hamel D, Visser M, Winter R, Pfister K, Rehbein S. 2013. Parasitic infections of domestic cats, Felis catus, in western Hungary. Veterinary Parasitology, 192, 33-42. 
5. da Silva Lima W, Ferreira Farago EC, Donascimento Mesquita M, Duarte Pacheco A, Fernandes Nunes da Silva Malavazi P, Salvador Oliveira H, Morelli S, Colombo M, Di Cesare A, Figueiredo de Souza S. 2021. First case of clinical cat aelurostrongylosis in the Brazilian Amazon: Clinical and molecular insights. Pathogens, 10 (5), 595.

6. Dantas-Torres F, Otranto D. 2014. Dogs, cats, parasites, and humans in Brazil: opening the black box. Parasites \& Vectors, 7, 22.

7. Diakou A, Di Cesare A, Accettura PM, Barros L, Iorio R, Paoletti B, Frangipane di Regalbono A, Halos L, Beugnet F, Traversa D. 2017. Intestinal parasites and vector-borne pathogens in stray and free-roaming cats living in continental and insular Greece. PLoS Neglected Tropical Diseases, 11(1), e0005335.

8. European Medicine Agency. Broadline ${ }^{\circledR}$ summary of product characteristics. 2014. https://www.ema.europa.eu/en/medicines/ veterinary/EPAR/broadline.

9. European Medicine Agency. NexGard ${ }^{\circledR}$ Combo: EPAR - Product information, 2021. European Medicine Agency. https://www. ema.europa.eu/en/medicines/veterinary/EPAR/nexgard.

10. Gupta A, Baker C, Wang H, Targa N, Pfefferkorn A, Tielemans E. 2021. Target animal safety evaluation of a novel topical combination of esafoxolaner, eprinomectin and praziquantel for cats. Parasite, 28, 18.

11. Jacobs DE, Arakawa A, Courtney CH, Gemmell MA, McCall JW, Myers GH, Vanparijs O. 1994. World Association for the Advancement of Veterinary Parasitology (W.A.A.V.P.) guidelines for evaluating the efficacy of anthelmintics for dogs and cats. Veterinary Parasitology, 52, 179-202.

12. Knaus M, Baker C, Alva R, Mitchell E, Irwin J, Shukullari E, Veliu A, Ibarra-Velarde F, Liebenberg J, Reinemeyer C, Tielemans E, Wakeland K, Johnson C. 2021. Efficacy of a novel topical combination of esafoxolaner, eprinomectin and praziquantel in cats against Toxocara cati and Dipylidium caninum. Parasite, 28, 28.

13. Knaus M, Abu-Madi MA, Ibarra-Velarde F, Kok DJ, Kusi I, Postoli R, Chester ST, Rosentel J, Alva R, Irwin J, Visser M, Winter R, Rehbein S. 2014. Efficacy of a novel topical fipronil, (S)-methoprene, eprinomectin and praziquantel combination against naturally acquired intestinal nematode and cestode infections in cats. Veterinary Parasitology, 202(1-2), 18-25.

14. Labarthe NV, Serrão ML, Ferreira AMR, Almeida NKO, Guerrero J. 2004. A survey of gastrointestinal helminths in cats of the metropolitan region of Rio de Janeiro Brazil. Veterinary Parasitology, 123, 133-139.

15. Little S, Adolph C, Downie K, Snider T, Reichard M. 2015. High prevalence of covert infection with gastrointestinal helminths in cats. Journal of American Animal Hospital Association, 51, 359-364.

16. Lucio-Forster A, Bowman D. 2011. Prevalence of fecal-borne parasites detected by centrifugal flotation in feline samples from two shelters in upstate New York. Journal of Feline Medicine and Surgery, 13, 300-303.

17. Marchiondo AA, Holdsworth PA, Fourie LJ, Rugg D, Hellmann K, Snyder DE, Dryden MW. 2013. World Association for the Advancement of Veterinary Parasitology (W.A.A.V.P.) second edition: Guidelines for evaluating the efficacy of parasiticides for the treatment, prevention and control of flea and tick infestations on dogs and cats. Veterinary Parasitology, 194, 84-97.

18. Mendes-de-Almeida F, Crissiuma AL, Gershony LC, Willi LMV, Paiva JP, Guerrero J, Labarthe N. 2011. Characterization of ectoparasites in an urban cat (Felis catus Linnaeus, 1758) population of Rio de Janeiro, Brazil. Parasitology Research, $108,1431-1435$.

19. Monteiro MF, Ramos RA, Calado AM, Lima VF, Ramos IC, Tenório RF, Faustino MA, Alves LC. 2016. Gastrointestinal parasites of cats in Brazil: frequency and zoonotic risk. Brazilian Journal of Veterinary Parasitology, 25, 254-257.

20. Morelli S, Diakou A, Colombo M, Di Cesare A, Barlaam A, Dimzas D, Traversa D. 2021. Cat respiratory nematodes: Current knowledge, novel data and warranted studies on clinical features, treatment and control. Pathogens, 10 (4), 454.

21. Nagamori Y, Payton ME, Duncan-Decocq R, Johnson EM. 2018. Fecal survey of parasites in free-roaming cats in northcentral Oklahoma, United States. Veterinary Parasitology Regional Studies and Reports, 14, 50-53.

22. Penagos-Tabares F, Lange MK, Chaparro-Gutiérrez JJ, Taubert A, Hermosilla C. 2018. Angiostrongylus vasorum and Aelurostrongylus abstrusus: Neglected and underestimated parasites in South America. Parasites \& Vectors, 11(1), 208.

23. Ramos DG, Scheremeta RG, Oliveira AC, Sinkoc AL, Pacheco Rde C. 2013. Survey of helminth parasites of cats from the metropolitan area of Cuiabá, Mato Grosso, Brazil. Brazilian Journal of Veterinary Parasitology, 22(2), 201-206.

24. Rehbein S, Capári B, Duscher G, Keidane D, Kirkova Z, Petkevičius S, Rapti D, Wagner A, Wagner T, Chester ST, Rosentel J, Tielemans E, Visser M, Winter R, Kley K, Knaus M. 2014. Efficacy against nematode and cestode infections and safety of a novel topical fipronil, (S)-methoprene, eprinomectin and praziquantel combination product in domestic cats under field conditions in Europe. Veterinary Parasitology, 202(1-2), $10-17$.

25. Tielemans E, Buellet P, Young D, Viljoen A, Liebenberg J, Prullage J. 2021. Efficacy of a novel topical combination of esafoxolaner, eprinomectin and praziquantel against adult cat flea Ctenocephalides felis and flea egg production in cats. Parasite, 28, 21.

26. Tielemans E, Erasmus H, Momberg M, Pfefferkorn A, Targa N, Chilakapati J, Gupta A. 2021. Safety evaluation of a novel topical combination of esafoxolaner, eprinomectin and praziquantel, in reproducing female cats. Parasite, 28, 20.

27. Tielemans E, Otsuki T, Cheesman T, Selmes F, Pfefferkorn A, Prullage J. 2021. Efficacy of a novel topical combination of esafoxolaner, eprinomectin and praziquantel against fleas in cats, under field conditions. Parasite, 28, 22.

28. Traversa D. 2012. Pet roundworms and hookworms: a continuing need for global worming. Parasites \& Vectors, 5, 91-110.

29. Traversa D, Di Cesare A. 2016. Diagnosis and management of lungworm infections in cats: Cornerstones, dilemmas and new avenues. Journal of Feline Medicine and Surgery, 18(1), 7-20.

30. Traversa D, Morelli S, Di Cesare A, Diakou A. 2021. Felid Cardiopulmonary nematodes: dilemmas solved and new questions posed. Pathogens, 10(1), 30.

31. Vercruysse J, Holdsworth P, Letonja T, Barth D, Conder G, Hamamoto K, Okano K. 2001. International harmonisation of Anthelmintic Efficacy Guidelines. Veterinary Parasitology, 96, 171-193.

32. Vercruysse J, Holdsworth P, Letonja T, Conder G, Hamamoto K, Okano K, Rehbein S. 2002. International harmonisation of Anthelmintic Efficacy Guidelines (Part 2). Veterinary Parasitology, 103, 277-297.

Cite this article as: Cutolo AA, Jardina DTG, De Vito GG, Grisi do Nascimento C, Heidmann MJ, Ferreira Nantes JD, Bassetto KV, Chagas IC, Pereira Junior EF, de Castro BG \& Tielemans E. 2022. Efficacy of two endectoparasiticide products combining fipronil and (S)-methoprene or esafoxolaner with eprinomectin and praziquantel against fleas and intestinal helminths in cats naturally infested in Brazil. Parasite 29, 12. 
Reviews, articles and short notes may be submitted. Fields include, but are not limited to: general, medical and veterinary parasitology; morphology, including ultrastructure; parasite systematics, including entomology, acarology, helminthology and protistology, and molecular analyses; molecular biology and biochemistry; immunology of parasitic diseases; host-parasite relationships; ecology and life history of parasites; epidemiology; therapeutics; new diagnostic tools.

All papers in Parasite are published in English. Manuscripts should have a broad interest and must not have been published or submitted elsewhere. No limit is imposed on the length of manuscripts.

Parasite (open-access) continues Parasite (print and online editions, 1994-2012) and Annales de Parasitologie Humaine et Comparée (1923-1993) and is the official journal of the Société Française de Parasitologie. 